\title{
Post-Master's Residency Programs: Enhancing the Development of New Professionals and Minority Recruitment in Academic and Research Libraries
}

\author{
Julie Brewer
}

Two of the greatest human resource concerns in academic and research libraries are the preparation of new library professionals and the recruitment of underrepresented minorities. The lack of practical experience and the changing competencies required of new graduates are discussed frequently at professional meetings and in the library literature. Diversity initiatives on college and university campuses and within the ALA also have raised awareness of the underrepresentation of minority librarians. Post-master's residency programs are one approach that academic and research libraries have used to address these continuing human resource concerns. This article examines post-master's residency programs from the perspective of former residents. The survey findings present important information for libraries that currently host residency programs or are considering implementing new residency programs in the future, as well as for library educators.

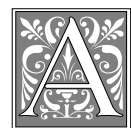

cademic and research libraries began experimenting with post-master's work experience programs in the 1940s in an effort to better prepare new library professionals. Two of the longest continuing post-master's programs are those hosted by the Library of Congress and the National Library of Medicine. The purpose of post-master's residency programs is to recruit highly talented graduates from library education programs and to prepare them for accelerated careers in academic and research libraries. Some residency programs provide advanced education and training for specialized careers in areas such as medical librarianship or conservation administration. Because professional positions in academic and research libraries often are highly specialized, most new librarians are unprepared to assume the level and depth of these responsibilities immediately following graduation. Many large academic and research libraries do not hire entry-level librarians. This practice restricts access to library careers

Julie Brewer is Associate Librarian at the University of Delaware Library; e-mail: jbrewer@udel.edu. 
in these areas and limits the pool of qualified candidates available for upper-level positions.

Approximately twenty years ago, a group of library educators and practitioners met to establish cooperative efforts in placing new library school graduates. ${ }^{1}$ The outcome of those meetings was a proposal to expand the availability of postmaster's work experience programs. The joint subcommittee of the Association of American Library Schools (AALS), predecessor of the current Association for Library and Information Science Education (ALISE), and the ACRL Personnel Administrators and Staff Development Officers Discussion Group proposed that each major research library create at least one permanent entry-level intern position. Although the proposal was not widely implemented, more than two dozen academic and research libraries have been identified as currently hosting a post-master's field experience program or as having hosted one in the past. ${ }^{2}$

In addition to preparing new professionals for careers in academic and research libraries, a number of residency programs started in the past ten to fifteen years also focus on the recruitment of minority librarians. Eighteen libraries currently host residency programs targeted to recent graduates from underrepresented racial and ethnic backgrounds or have hosted such a program in the past. ${ }^{3}$ Minority residency programs are key affirmative action initiatives at many academic and research institutions.

The ACRL Strategic Plan acknowledges the need to "support recruitment efforts to bring into the profession those individuals who will enrich the diversity of the profession." ${ }^{4}$ Academic libraries are concerned about creating a welcoming environment and providing appropriate services to the increasing number of minority students on their college and university campuses. Yet, addressing these concerns is difficult with so few minority librarians.
The ALA Office for Library Personnel Resources (OLPR) 1991 data indicate a total of 2,850 minority librarians in academic and public libraries. The OLPR data are presented in table 1 as a distribution of librarians by racial, ethnic, and gender groups in academic and public libraries. ${ }^{5}$ These data show that librarianship in general, and academic librarianship in particular, continues to be a predominately white, female profession.

\section{A number of residency programs started in the past ten to fifteen years also focus on the recruitment of minority librarians.}

Although the need for attracting more minorities to academic and research libraries is widely understood, the practice of targeting residency programs to minority graduates has raised some concerns. The ACRL Task Force on Recruitment of Underrepresented Minorities identified a number of potential stumbling blocks associated with minority residency programs in its 1990 final report. ${ }^{6}$ A primary concern is that minority graduates selected for these programs will be stigmatized as underprepared, lacking skills, or otherwise unqualified for permanent entry-level professional positions.

Library educators have shown continued interest in residency programs by working to establish general guidelines for the design, operation, and evaluation of post-master's work experience programs. The guidelines adopted by ALISE in 1992 outline programmatic standards. ${ }^{7}$ The definition of terms referring to graduate and postgraduate work experience programs is an important contribution of the ALISE guidelines. The guidelines define internships as structured preprofessional work experiences that take place either during or after graduate course work but preceding the degree, usually for a short amount of time. Residencies are defined as post-degree work experiences de- 


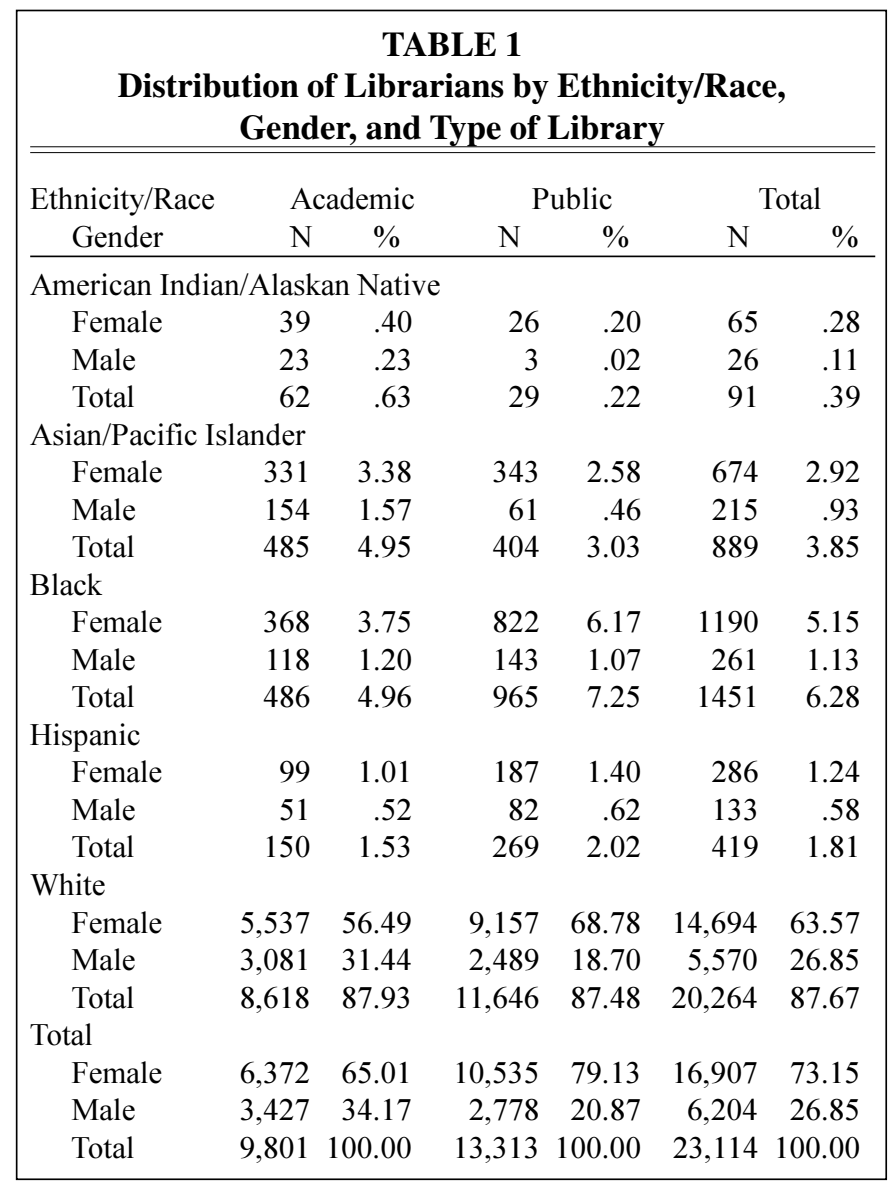

signed as entry-level programs for professionals who have recently received an MLS. Fellowships are midcareer experiences designed to assist librarians who already have some professional experience to develop a specialty or to improve management skills. This article uses the term residency as defined by the ALISE guidelines.

\section{Rationale for Research}

Although most post-master's residency programs have existed for many years, very little information is available about them. The library literature provides some descriptive information about individual programs, yet no objective data on their quality and value exist. ${ }^{8}$ Little is known about how residency programs affect career development, how targeted programs contribute to minority recruitment, or what the value is of residency programs in academic and research libraries.

The general lack of information about residency programs is a problem from

The lack of information and misconceptions about residency programs among staff in host libraries can affect the quality of the residency experience.

many perspectives. Without adequate information, library educators have difficulty advising students, and new graduates 
have difficulty making informed career choices. The lack of information and misconceptions about residency programs among staff in host libraries can affect the quality of the residency experience. Moreover, residents may feel isolated without a broader understanding of similar programs and contacts in other libraries.

A number of efforts to gather information and facilitate communication about residency programs have been made in the past few years. OLPR hosted two discussion group meetings at the 1991 Annual Conference in Atlanta and at the 1995 Midwinter Meeting in Philadelphia. In 1992, the Association for Research Libraries (ARL) published a survey of member libraries in SPEC Kit \#188, Internship, Residency, and Fellowship Programs in ARL Libraries, which includes descriptive information about six residency programs. ${ }^{9}$ ARL also hosted two seminars in 1996 on implementing post-master's residency programs.

\section{Research Focus and Methodology}

To expand on these efforts, OLPR designed a study with three primary objectives: to collect qualitative data about residency programs from the perspective of former program participants; to track the career development of former postmaster's residents; and to understand differences in perspectives, if any, between residents who participated in programs targeted to minorities and those who participated in open recruitment programs.

In May 1994, a sixty-question survey instrument was mailed to 230 former post-master's residents. The instrument was designed to gather information about residency experiences from the perspective of former program participants. It did not ask respondents to identify the institutions that had hosted their residency programs. Rather, it focused on general issues of recruitment, program design, professional development, and attitudes. The survey asked respondents to recom-

\begin{tabular}{|cc|}
\hline \multicolumn{2}{|c|}{ TABLE 2} \\
Characteristics of Respondents \\
\hline \hline Age* & $\%$ \\
\hline $21-25$ & 28 \\
$26-30$ & 42 \\
$31-35$ & 18 \\
$36-39$ & 5 \\
$40+$ & 4 \\
No response & 3 \\
Total & 100 \\
Ethnicity/Race & $\%$ \\
\hline Black/African American & 13 \\
Asian/Asian American & 3 \\
Hispanic & 4 \\
American Indian/ & \\
Alaskan Native & 1 \\
White & 77 \\
No response & 2 \\
Total & 100 \\
Gender & $\%$ \\
\hline Female & 76 \\
Male & 24 \\
Total & 100 \\
\hline * Age at beginning of residency program \\
\hline
\end{tabular}

mend ways to improve residency programs and to offer advice for those considering this type of career development opportunity.

Identifying the potential survey population was a challenge because no central information about residency programs exists, nor do many of the institutions have extensive records on former residents and their current locations. Although a few program coordinators provided lists, most people who volunteered to participate noticed the announcement of the study on listservs such as LIBPER, LIBADMIN, and JESSE, and in various professional newsletters. Nearly all the volunteers responded via e-mail, and many suggested the names of colleagues who had worked in their programs. Based on this solicitation for volunteers, 230 former residents were identified and sent survey instruments. 
One hundred and nine former residents, or 47 percent of the survey population, completed and returned the survey instruments. The respondents were predominately white women between twenty-one and thirty years of age at the beginning of their residency program. Most respondents had two years or less of preprofessional library experience prior to their residency (see table 2).

Respondents reported that their residency programs varied in length and structure, and by type of library. Most programs were one year or less in length. Typically, they were structured as a rotation through several areas of the library followed by a specific project or assignment. Most programs hosted more than one resident at a time. The programs were approximately split between academic and government libraries (see table 3).

Readers should be aware that these program characteristics and other survey findings may be skewed in overrepresenting the older, larger residency programs in government libraries, such as the National Library of Medicine and the Library of Congress. The survey population had a high percentage of former residents from these larger programs which host many residents at one time and have been operating for several decades. Most residency programs started in the past ten to fifteen years generally host one to three residents at a time. The survey population naturally had a lower number of former residents from these programs.

\section{Findings and Implications}

Libraries use a variety of recruitment methods to attract new professionals to residency programs, including traditional employment tools such as position announcements in professional publications, as well as brochures distributed to graduate library education programs. Most former residents learned of the residency opportunity from a faculty or staff person in their graduate library education program. Residents tended to apply to

\begin{tabular}{|c|c|}
\hline \multicolumn{2}{|c|}{$\begin{array}{c}\text { TABLE } 3 \\
\text { Characteristics of } \\
\text { Residency Programs }\end{array}$} \\
\hline Type of Library & $\%$ \\
\hline Government & 54 \\
\hline Academic & 42 \\
\hline Corporate & 1 \\
\hline Other & 2 \\
\hline No response & 1 \\
\hline Total & 100 \\
\hline Length & $\%$ \\
\hline 1 year (or less) & 70 \\
\hline 2 years & 28 \\
\hline More than 2 years & 2 \\
\hline Total & 100 \\
\hline Minority Focus & $\%$ \\
\hline No & 82 \\
\hline Yes & 17 \\
\hline No response & 1 \\
\hline Total & 100 \\
\hline
\end{tabular}

specific programs rather than seek residency experiences in general. The majority of respondents applied to only one residency program. The key factors in choosing a residency position were the reputation or prestige of the library, the institution, or the people involved; and the opportunity to gain a breadth of professional library experiences.

Survey respondents generally were

Orientation to the residency program and library and overall training were rated as good or very good by 83 percent of respondents.

very pleased with the management of their residency programs. Orientation to the residency program and library and overall training were rated as good or very good by 83 percent of respondents. Most (93\%) felt their assignments matched their interests and abilities reasonably well or very well. Most (72\%) also 


\begin{tabular}{|c|c|c|}
\hline \multicolumn{3}{|c|}{$\begin{array}{c}\text { TABLE } 4 \\
\text { Attributes of Supervisors } \\
\end{array}$} \\
\hline Attribute & $\begin{array}{c}\text { Most } \\
\text { Important }\end{array}$ & $\begin{array}{l}\text { Next Most } \\
\text { Important }\end{array}$ \\
\hline Availability & $14 \%$ & $13 \%$ \\
\hline Flexibility & 2 & 15 \\
\hline $\begin{array}{l}\text { Technical } \\
\text { expertise }\end{array}$ & 6 & 6 \\
\hline $\begin{array}{l}\text { Familiarity with } \\
\text { staff and } \\
\text { organization }\end{array}$ & 11 & 15 \\
\hline Mentoring skills & 42 & 12 \\
\hline $\begin{array}{l}\text { Support for } \\
\text { residency } \\
\text { program }\end{array}$ & 5 & 7 \\
\hline $\begin{array}{l}\text { Ability to provide } \\
\text { constructive } \\
\text { feedback }\end{array}$ & 7 & 20 \\
\hline Other & 7 & 2 \\
\hline No response & 6 & 10 \\
\hline Total & $\overline{100}$ & 100 \\
\hline
\end{tabular}

felt the expectations for their responsibilities were reasonably well defined or very well defined.

Most former residents rated their relationship with the program coordinator as good or excellent. They reported regular meetings with program coordinators several times a year, although many met more frequently. Exceptional program coordinators were noted for providing a broad perspective of the organization, providing moral support, creating learning opportunities, and providing feedback.

More than half of the respondents had two or more supervisors during their residency. Having multiple supervisors was viewed as no problem or an advantage in most instances. Former residents identified mentoring skills and ability to provide constructive feedback as the two most important attributes for supervisors. Although respondents gave their supervisors the highest ratings for familiarity with library staff and organization and support for the residency program, which are im- portant elements of mentoring, they rated their supervisors' overall mentoring skills relatively low. This is an important finding for program coordinators. Mentoring skills may need to be emphasized for all library employees who work with residents (see table 4).

Former residents rated in-house seminars, interaction with other residents, and travel funding to regional and national meetings as the three most important development opportunities. Responses to open-ended questions on peer interaction with other residents were particularly enthusiastic. Respondents reported that peer residents provided social camaraderie, moral support, opportunities for group projects, shared professional knowledge and expertise, motivation, quicker learning, different perspectives, and "career-long" professional relationships. One respondent observed, however, that an optimal number of four to five residents was more manageable than situations where there were seven or more residents.

Most respondents (85\%) felt they were treated as professional librarians most of the time. Examples of work felt to be less than professional included: filing in the card catalog, shelf reading, manual tasks prior to personal computers, physically moving books during building move, serial check-in, rearranging supply cabinet, copy cataloging, working the information desk, inventorying the reference collection, routine file maintenance of online catalog, photocopying, checking in mail, searching interlibrary loan requests, and processing and shelving books. However, former residents were more disturbed by patronizing attitudes than by work assignments they felt to be less than professional. A number of respondents felt talked-down-to during seminars and felt they were treated as students. Some were made to feel that their opinions were of no value or that they were powerless because of the temporary nature of their position. 


\begin{tabular}{|lr|}
\hline \multicolumn{2}{|c|}{$\begin{array}{c}\text { TABLE 5 } \\
\text { Position Titles }\end{array}$} \\
\hline \hline Title & $\mathbf{\%}$ \\
\hline Associate & 40 \\
Intern & 28 \\
Resident & 22 \\
Other/No answer & $\mathbf{1 0}$ \\
\cline { 2 - 2 } Total & $\mathbf{1 0 0}$ \\
\hline
\end{tabular}

Most respondents (90\%) felt involved as a contributing member of the organization. Examples of involvement included working on critical projects that contributed to the library mission, being included as members of a team, conducting training sessions for staff, presenting results of professional work to peers, and having opinions and feedback solicited. Anumber of respondents said they would have liked to have been included on committees.

The survey data were inconclusive in measuring the career development of former residents. Respondents were asked to name their first position or title following the residency program, as well as their current position or title. Because there is little uniformity in titles in academic libraries, better measures are needed to track career development. However, survey respondents regard their residency experiences as significant elements in their career development. Although approximately half (51\%) felt they would have had little difficulty finding another entry-level position (rather than the residency position), most ( $88 \%$ ) said the residency experience contributed to some extent, or to a great extent, to subsequent jobs. Eightythree percent said their career path would have been different without the residency experience.

The survey results indicate that host libraries have differing views of their role in retaining residents and helping residents to find subsequent professional positions. Although some programs aim to recruit and prepare new librarians for careers in academic and research librar- ies, or specifically in medical libraries, other programs may be using residency programs to screen future employees for that individual institution. Approximately two-thirds of the respondents (64\%) were offered professional positions in their host library following their residency. Fifty-one percent accepted the offer; 13 percent declined.

A wide array of titles are assigned to residents in different programs (see table 5). Although most respondents were unconcerned about the titles, some former residents who worked in medical libraries felt the term intern was confusing because it also is used to designate medical students preparing to become physicians. Others expressed discomfort with the term intern for its less-than-professional connotation. A few respondents commented on being treated as a continuing student rather than a professional librarian.

Minority residents also expressed some discomfort with their titles. Some of the titles used in programs targeted to graduates from underrepresented racial and ethnic groups include minority intern, affirmative action intern, and minority resident. Some respondents felt discomfort when their minority status was overemphasized. The emphasis on minority status unnecessarily focused on differences or led to perceptions that these residents were substandard. The term affirmative action in the title was very awkward for one respondent, who felt the confusion and stigma associated with the public debate about affirmative action.

Nineteen respondents reported working in residency programs targeted to racial and ethnic minorities. The survey asked residents from these programs to comment on their treatment. Seventy-five percent felt their racial or ethnic background had a positive role or no role in their residency program. A few commented that their racial or ethnic background had both a positive and a negative role. And one respondent felt that racial or ethnic background had a 
negative role.

Minority respondents felt that their racial and ethnic background was important in adding diversity to predominantly white library staffs. It provided an opportunity for students and staff to work with minorities. Most often, the residents were accepted as professionals who happened to be minorities. Racial and ethnic background also determined some assignments directed to minority residents. This was a positive experience when the assignment related to the resident's area of interest. In other situations, minority residents were looked to as "experts" on questions dealing with ethnic issues.

Residency programs seem to be effective recruitment tools for attracting minorities and other individuals for shortterm, temporary assignments who would not consider moving to a specific geographic location for more permanent positions. Survey responses indicated the residency programs succeed in recruiting individuals to academic and research libraries who otherwise were not considering careers in these areas. One minority respondent wrote: "The program was the single most important factor in my choosing employment in an academic library."

Overall, the response to the survey was overwhelmingly positive. An overwhelming amount of support and enthusiasm for residency programs was expressed in the survey responses. Nearly all respondents $(97 \%)$ said they enjoyed their residency experience very much or most of the time. Given the opportunity to apply for the same or similar residency program, 93 percent said they would do it again.

Typical words used to describe the residency experience include: "valuable," "great," "fantastic," and "excellent." The most frequent remarks suggest that residency programs provide unique learning opportunities and are important foundations for beginning careers. Residents found the mentoring and networking invaluable. The programs exposed resi- dents to a breadth of professional experiences typically unavailable in other entry-level positions or traditional career paths. Those who were uncommitted to specific career plans valued the opportunity to explore and test their interest in academic and research libraries, particularly in light of the rigorous promotion and tenure system at most institutions.

A certain sense of delight and renewed appreciation for their residency experiences came through in written comments. Respondents frequently commented that at the beginning of their programs they had no idea of the value they would later attach to the experience. Reflection and hindsight seemed to be very satisfying for most respondents, although two had negative experiences to relate: limited opportunities and exposure, and poor relations with supervisors. Overall, respondents continue to enjoy the careers they have built on their residency experiences. Ninety-three percent report enjoying their current work very much or most of the time.

Another measure of the high regard former residents have for these programs is the volume of written responses. More than 80 percent of the respondents offer advice to supervisors and program coordinators. Examples of advice include: "emphasize big picture"; "provide broad exposure"; "appreciate different background and interests of residents and try to design parts of their program to match those areas"; "provide more opportunities for projects that will benefit the library and challenge the residents"; "encourage mentoring relationships"; "clearly define goals of the program"; "be accessible"; "be flexible." Numerous responses emphasized the need to make programs two years long, with at least one peer resident.

An even larger number of written responses $(84 \%)$ were directed to new master's graduates considering residency programs. Nearly all respondents said, "Do it!" They emphasized the networking and learning opportunities, and sug- 
gested that residents need to be willing to explore all aspects of librarianship. One respondent suggested that, "You may find your niche is not what you expected." Other advice included: "be respectful and diplomatic"; "be flexible and open-minded"; "be prepared to be very self-motivated"; "be aware of organizational politics"; "make a site visit"; "talk to residents who have been in the program to assess support for the program and placement assistance."

\section{Conclusions}

The survey findings indicate that postmaster's residency programs are valuable recruitment tools that provide positive career development opportunities for new library professionals. Most former residents are extremely pleased with their experiences and encourage others to take advantage of these unique career development opportunities. Post-master's residency programs provide opportunities for new graduates to gain substantial professional experience and accelerated training at the beginning of their careers which generally are not available in traditional entry-level positions. Although the study was inconclusive on how residency programs affect individual career patterns, most former residents feel their experiences were invaluable.

Academic and research libraries benefit from residency programs by having a continuous pool of talented, well-pre- pared, new professionals. Given the highly specialized nature of positions in academic and research libraries, access to, and recruitment for, careers in these areas will always be difficult. Residency programs address both of these concerns, as well as attract minority librarians to careers in academic and research libraries. However, recruiting minority students to graduate library education programs needs to be a continuing priority for the library profession.

And finally, residency programs may offer a new flexibility to large academic and research libraries. The availability of temporary, new professionals allows large organizations the opportunity to respond to quickly shifting priorities. Some libraries use residency assignments as opportunities to experiment with the design of new positions and services. In addition to being effective strategies for preparing new library professionals and recruiting underrepresented minorities, postmaster's residency programs address emerging human resource needs for flexibility in rapidly changing organizations.

The author expresses deep gratitude to former Associate Professor Barry Morstain, College of Urban Affairs and Public Policy, University of Delaware, for his encouragement, critical review of research design and analysis, and lifelong commitment to enhancing employment opportunities for all.

\section{Notes}

1. Margo C. Trumpeter and Paul Gherman, "A Post-Master's Degree Internship Program," Library Journal 105 (June 1980): 1366-69.

2. These included Auburn University, Cleveland State University, Cornell University, Iowa State University, Library of Congress, Miami University (Ohio), National Library of Medicine, Ohio State University, Smithsonian Institution Libraries, Stanford University, SUNY-Buffalo, University of California, University of California-Berkeley, University of California-Santa Barbara, University of Colorado-Denver, University of Delaware, University of Illinois at Chicago, University of Illinois at Urbana-Champaign, University of Iowa, University of Michigan, University of Minnesota, University of Missouri-Columbia, University of Missouri-St. Louis, Wright State University, Yale University, and various Conservation Administration programs supported by the Andrew W. Mellon Foundation.

3. These include Auburn University, Cleveland State University, Cornell University, Iowa State University, Miami University (Ohio), Ohio State University, Smithsonian Institution Libraries, Stanford University, State University of New York-Buffalo, University of California, Uni- 
versity of California-Berkeley, University of California-Santa Barbara, University of Delaware, University of Iowa, University of Minnesota, University of Missouri-St. Louis, Wright State University, and Yale University.

4. "ACRL Charts New Direction," College \& Research Libraries News 56 (Sept. 1995): 571.

5. "Academic and Public Librarians: Data by Race, Ethnicity \& Sex, 1991" (Chicago: ALA, 1991, photocopy), 3.

6. Janice Beaudin et al., "Recruiting the Under-Represented to Academic Libraries," College \& Research Libraries News 51 (Dec. 1990): 1024.

7. "Guidelines for Practices and Principles in the Design, Operation, and Evaluaton of PostMaster's Residency Programs" (Association for Library and Informaton Science Education, 1992, photocopy).

8. For example, see Jon E. Cawthorne and Teri B. Weil, "Internships/Residencies: Exploring the Possibilities for the Future," in In Our Own Voices: The Changing Face of Librarianship, ed. Teresa Y. Neely and Khafre K. Abif (Lanham, Md.: Scarecrow Pr., 1996): 45-71; Jose Diaz and Kristina Starkus, "Increasing Minority Representation in Academic Libraries: The Minority Librarian Intern Program at the Ohio State University," CERL 55 (Jan. 1994): 41-46; Deborah Hollis, "On the Ambiguous Side: Experiences in a Predominantly White and Female Profession," in In Our Own Voices: The Changing Face of Librarianship, ed. Teresa Y. Neely and Khafre K. Abif (Lanham, Md.: Scarecrow Pr., 1996): 139-54; Joseph A. Boissé and Connie V. Dowell, "Increasing Minority Librarians in Academic Research Libraries," Library Journal 112 (Apr. 1987): 52-54; Sheila D. Creth, "The First Two Years' Experience," Library Journal 111 (Feb. 1986): 121-24; Richard M. Doughery, "The Underlying Rationale," Library Journal 111 (Feb. 1986): 118-20; Betty Glass, "A Time of Transition," Library Journal 111 (Feb. 1986): 127-28; Sarah Shoemaker, "A Unique Experience," Library Journal 111 (Feb. 1986): 125-26; Molly Mahony, "Preparation for the Future," Library Journal 111 (Feb. 1986): 129-30; Richard M. Dougherty and Wendy P. Lougee, "Research Library Residencies: A New Model of Professional Development," Library Journal 108 (July 1983): 1322-24.

9. "Internship, Residency, and Fellowship Programs in ARL Libraries," SPEC Kit\#188 (Washington, D.C.: ARL, 1992). 